\title{
A cross-sectional study of prevalence and risk factors for childhood asthma in Ahvaz city, Iran
}

\author{
Heshmatollah Tavakol' ${ }^{1}$, Zahra Rahimi², Maria Cheraghi ${ }^{3}$, Fathemeh Ghatfan ${ }^{4,5}$, Zahra Baji ${ }^{5}$, Hossein Rahmani ${ }^{6,7}$ \\ ${ }^{1}$ Department of Medicine, Ahvaz Jundishapur University of Medical Sciences, Ahvaz, Iran \\ ${ }^{2}$ Health Center of Dashte Azadegan, Ahvaz Jundishapur University of Medical Sciences, Ahvaz, Iran \\ ${ }^{3}$ Deputy of the Research, Social Determinate of Health Research Center, Ahvaz Jundishapur University of Medical Sciences, Ahvaz, Iran \\ ${ }^{4}$ Student Research Committee, Ahvaz Jundishapur University of Medical Sciences, Ahvaz, Iran \\ ${ }^{5}$ Department of Public Health, School of Health, Ahvaz Jundishapur University of Medical Sciences, Ahvaz, Iran \\ ${ }^{6}$ Departments of Toxicology, Shahreza Branch, Islamic Azad University, Shahreza, Iran \\ ${ }^{7}$ Medical Research Center, Jundishapur Health Development Co, Tehran, Iran
}

Postep Derm Alergol 2015; XXXII (4): 268-273

DOI: $10.5114 /$ pdia.2015.53322

\begin{abstract}
Introduction: Childhood asthma is the main public health problem in world, and dramatically has increased in developed as well as developing countries.

Aim: To assess prevalence and risk factors for asthma based on ISAAC questionnaire.

Material and methods: It was a cross-sectional school population-based study which was carried out on 1803 school children aged 6-7 and 13-14 in Ahvaz city, Khuzestan, south west of Iran, in 2011. The International Study of Asthma and Allergies in Childhood (ISAAC) questionnaire was used as a tool to identify prevalence of asthma. Chi-square $\left(\chi^{2}\right)$ test was then used to identify possible potential risk factors associated with asthma. Logistic regression analysis was then applied to determine the various potential risk factors associated with asthma. Data were entered and analyzed using SPSS (version 17) statistical analysis software. The significant level in this study was considered 0.05. Results: The overall prevalence of asthma among school children was $4.9 \%$, but in males it was $5.5 \%$ and in females $-4.3 \%$. Also findings have demonstrated that prevalence of asthma was higher among 13-14 years age group (6.1\%) as compared to children aged 6-7 (3.7\%). The prevalence of wheeze in the last 12 months, wheeze after exercise and playing was $18.1 \%, 13.9 \%$, and $8.4 \%$ respectively. Prevalence of dry cough at night was reported in $17.6 \%$. Prevalence of asthma was highest in winter (2.6\%).

Conclusions: Prevalence of asthma in children was higher in males than females and prevalence of allergic symptoms will be increased with high air pollution. Family history of asthma was a strong risk factor for childhood asthma.
\end{abstract}

Key words: prevalence, asthma, children, risk factors, Ahvaz.

\section{Introduction}

Asthma is a common chronic respiratory disease affecting children; it is a major health problem in both developed and developing countries [1-3]. The prevalence of childhood asthma and the morbidity related to asthma are both increasing, and occur in approximately $7-10 \%$ of the pediatric population and it is the leading cause of childhood morbidity [4-8]. This chronic disease of the airways may cause wheezing, breathlessness, chest tightness and nighttime or early morning coughing, it is often reversible either spontaneously or with treatment [2].

The International Study of Asthma and Allergies in Childhood (ISAAC) questionnaire was used as a tool to compare prevalence, severity, risk factors, and secular trend for asthma within and between countries. This study demonstrates the prevalence and severity of illness according to base data to assess future trends $[8,9]$. The study was performed in 3 phases. The first phase was carried out on more than 70,000 children in two age groups (7-6 and 13-14 years) in 156 centers and 56 countries. The second phase was conducted in 36 centers and 22 countries to further explore the potential role of risk factors and protective factors that were observed indifferent countries of the first phase [10]. The third phase took place about 5 to 10 years after the first phase to assess the prevalence of asthma and allergies in areas where the first phase was implemented to provide testing hypotheses at the individual level according to the results of the first phase [11]. The ISAAC program was also

Address for correspondence: Maria Cheraghi, Social Determinate of Health Research Center, Ahvaz Jundishapur University of Medical Sciences, PO Box 61335715751, Ahvaz, Iran, phone: +98 9163413086, e-mail: mariacheraghi@gmail.com Received: 1.09.2014, accepted: 24.02.2015. 
launched in Iran in 1997 with the first phase carried out by the Institute of Tuberculosis and Lung Disease, then in 2000-2001, the third phase was conducted in Rashtand Tehran cities, Iran. Now, it is being conducted in different cities such as Shahr-e-Kord, Isfahan, Kashan, Zanjan, Birjand, Tabriz, Babol, but in amore limited form [1].

Ahvazisone of the major Iranian cities, and has a high prevalence of asthma due to its hot and humid weather, overpopulation, industrial centers, and recently installed dust collectors.

\section{Aim}

Our study aimed to assess the prevalence of asthma and its associated risk factors based on the ISAAC questionnaire.

\section{Material and methods}

\section{Method}

This was a cross-sectional school population-based study in which parents of school children aged 6-7 and 13-14 years old in Ahvaz city were administered an ISAAC questionnaire and an additional set of questions that captured the presence of potential risk factors known to be associated with asthma during the school year 2011-2012.

\section{Study population}

In Ahvaz city, there are four educational regions. Then, 16 schools were randomly selected as the cluster. Totally, 1803 school children participated in this study, 929 and 874 school children were among 6-7 years old and 13-14 years old groups, respectively, their age was confirmed as per school records. The study was approved by the local independent ethics committee before the start of the study.

Prior permissions from educational authorities, school principals, and class teachers were obtained, and then written informed consent was taken from parents' children between the ages of 6-7 and 13-14, and objectives of this study were explained.

\section{Research tools}

The International Study of Asthma and Allergies in Childhood (ISAAC) questionnaire was used as a tool to identify prevalence of asthma. This tool has been validated worldwide and within the country and has been used to determine asthma prevalence. An additional set of questions providing information on potential risk factors associated with asthma was also added. The questionnaire included questions about environmental exposures; parental smoking, presence or absence of separate kitchen, ventilation at home, presence of cockroaches and pets at home, presence of preterm birth, type of delivery, breastfeeding during the first 6 months of life, number of family members, number of siblings, snoring during sleep, parental education, and parental occupation. Asthma in the study population was defined as per the ISAAC study criteria, namely, "presence of wheezing or whistling in the chest, chest sounding wheezy during or after exercise, and dry cough at night; apart from a cough associated with a cold or chest infection" during the past 12 months, or if they answered "yes" to the question "has your child ever had asthma?".

The original draft of parents' information sheet, consent form and validated questionnaire were made in English and translated into the local language (Persian) by an expert on this subject. The Persian translation was subsequently back translated into English, which has been done by three different categories of people (a professional doctor, a qualified non-medical graduate and a lay person).

The questionnaire was completed by parents of school children aged 6-7, and school children aged 13-14 themselves, supervised by trained interviewers. If the parents were illiterate or unfamiliar in Farsi, trained interviewers had been used.

\section{Statistical analysis}

A sample size of 1803 was calculated based on the results of another study conducted by Shakurnia et al. [4], on 2401 school children in Ahvaz city.

All the data collected from the returned questionnaires were double-entered by data input clerks into Epiinfo. The data set was then validated and consolidated by a single data manager. Prevalence of asthma in the study population was calculated as a percentage of children having defined asthma symptoms based on sex and age. Chi-square $\left(\chi^{2}\right)$ test was then used to identify possible potential risk factors associated with asthma. Logistic regression analysis was then applied to determine the various potential risk factors associated with asthma. The impact of the risk factors was described in terms of the odds ratio. The analysis of data was performed by the SPSS (version 19.0, SPSS, Inc., Chicago, IL, USA) software package. The significant level in this study was considered 0.05 .

\section{Results}

In this study, 1803 questionnaires were distributed so that 929 and 874 questionnaires were respectively completed by parents in the age groups 6-7 years and by school children aged 13-14 themselves. In our research, $51.5 \%$ were aged $6-7$, and $48.5 \%$ aged $13-14$. Almost half of participants (50.1\%) were boy children, and $49.8 \%$ of them were girl children.

The overall prevalence of asthma among school children was $4.9 \%$, and in males it was 5.5\% and in females $-4.3 \%$. Also the findings have demonstrated that preva- 


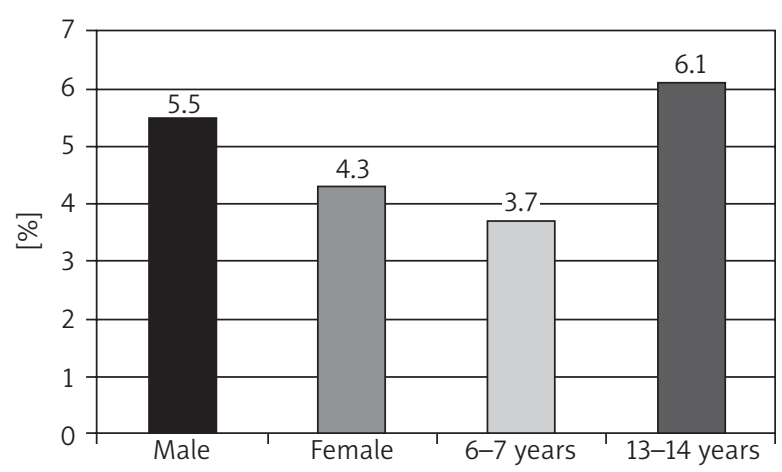

Figure 1. Overall prevalence of childhood asthma in Ahvaz city

lence of asthma was higher in the 13-14 years age group (6.1\%) as compared to children aged 6-7 (3.7\%) (Figure 1). The prevalence of wheeze in the last 12 months, wheeze after exercise and playing was $18.1 \%, 13.9 \%$, and $8.4 \%$, respectively. Prevalence of dry cough at night was reported in $17.6 \%$. Prevalence of asthma was highest in winter (2.6\%). The prevalence of family history of asthma in parents of children was $5 \%$ in the father's family and $5.1 \%$ in the maternal family. Prevalence of asthma symptoms was higher in boys than girls (Table 1, Figure 2). Prevalence of asthma symptoms according to age-wise is shown in Figure 3.
As to risk factors associated with asthma, results indicated that the frequency of birth weight of less than $2500 \mathrm{~g}$ was $17.2 \%$ in boys and $15.4 \%$ in girls. Asthma was more common for boys in autumn and for girls in winter. In other words, $30.6 \%$ of boy children and $38 \%$ of girl children reported asthma in autumn and winter, respectively. The age of onset of asthma was more than 5 years in boys and $1-5$ years in girls. Approximately $40 \%$ of boy children suffered from asthma. Results from the logistic regression model according to sex-wise have demonstrated that in male asthmatic school children, there was an association between allergy symptoms, including cough, headache, runny nose and runny eyes and increase in air pollution $(p<0.0001, O R=0.23$; $p=0.015, O R=0.22 ; p=0.012, O R=0.074)$, but a significant association was not seen in female asthmatic school children. As seen in Table 2, most of children (55.2\%) aged 6-7 were born through Cesarean delivery, and $63.2 \%$ of participants aged $13-14$ had natural childbirth. $10.7 \%$ of them in the 6-7 years age group and $24.5 \%$ in the $13-14$ years age group had birth weight of less than $2500 \mathrm{~g}$.

No association was observed between age groups, blood groups, type of delivery, age at onset of asthma, breastfeeding conditions, maternal family history of asthma, presence of a separate kitchen, presence of cockroaches or pets at home, presence of wall damp-

Table 1. Odds ratio of respiratory symptoms in childhood asthma sex-wise

\begin{tabular}{|c|c|c|c|c|}
\hline Variable & Gender & $\%$ & OR $(95 \% \mathrm{Cl})$ & Value of $p$ \\
\hline \multirow[t]{2}{*}{ Ever wheeze } & Male & 20.7 & $9.78(5.56-17.86)$ & \multirow[t]{2}{*}{$<0.001$} \\
\hline & Female & 16 & $1.33(0.57-3.11)$ & \\
\hline \multirow[t]{2}{*}{ Wheeze during the last 12 months } & Male & 0.8 & $8.85(5.11-15.33)$ & \multirow[t]{2}{*}{$<0.001$} \\
\hline & Female & 12.4 & $1.28(0.48-3.38)$ & \\
\hline \multirow[t]{2}{*}{ Wheeze limiting breath } & Male & 3.8 & $6.60(3.00-14.55)$ & \multirow[t]{2}{*}{$<0.001$} \\
\hline & Female & 4 & $0.67(0.09-5.04)$ & \\
\hline \multirow[t]{2}{*}{ Ever asthma } & Male & 5.5 & $622.5(198.49-1952.27)$ & \multirow[t]{2}{*}{$<0.001$} \\
\hline & Female & 3.4 & $0.629(0.084-4.71)$ & \\
\hline \multirow[t]{2}{*}{ Wheeze after exercises } & Male & 8.9 & $8.39(4.67-15.06)$ & \multirow[t]{2}{*}{$<0.001$} \\
\hline & Female & 8.7 & $0.30(0.04-0.23)$ & \\
\hline \multirow[t]{2}{*}{ Dry cough } & Male & 18 & $4.62(2.69-7.93)$ & \multirow{2}{*}{$\begin{array}{c}<0.001 \\
0.06\end{array}$} \\
\hline & Female & 17.9 & $0.27(0.064-1.13)$ & \\
\hline \multirow[t]{2}{*}{ Family history of asthma in the father } & Male & 5.3 & $5.32(2.53-11.17)$ & \multirow[t]{2}{*}{$<0.001$} \\
\hline & Female & 5.6 & $0.72(0.06-3.71)$ & \\
\hline \multirow[t]{2}{*}{ Family history of asthma in the mother } & Male & 5.8 & $2.61(1.11-6.13)$ & \multirow[t]{2}{*}{$<0.05$} \\
\hline & Female & 5.7 & $0.52(0.07-3.93)$ & \\
\hline \multirow[t]{2}{*}{ Father's smoking } & Male & 26.8 & $0.76(0.4-1.43)$ & \multirow[t]{2}{*}{0.45} \\
\hline & Female & 18.5 & $1.27(0.57-0.85)$ & \\
\hline \multirow[t]{2}{*}{ Mother's smoking } & Male & 1.3 & $2.97(0.63-14.08)$ & \multirow{2}{*}{$\begin{array}{l}0.18 \\
1.00\end{array}$} \\
\hline & Female & 6.0 & $1.04(1.03-1.05)$ & \\
\hline
\end{tabular}




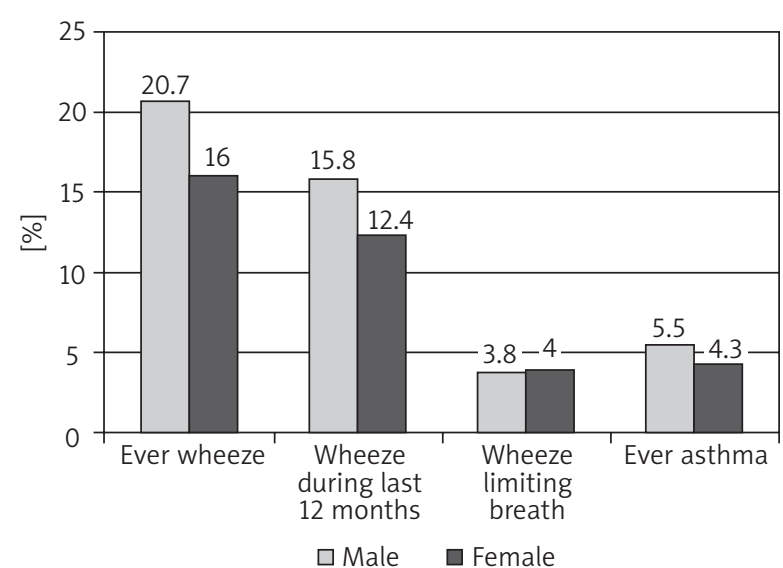

Figure 2. Prevalence of respiratory symptoms in childhood asthma between males and females

ness, time spent on cooking at home, weight at birth, birth order in the group aged 6-7, type of delivery, type of family (nuclear or extended), mother's age at birth, presence of preterm birth, breastfeeding during the first 6 months of life, injecting DTP and BCG vaccines, number of family members, history of and years of parents' smoking, father's education in the 7-6 years age group, maternal education, and food allergies and sensitivities in the 13-14 years age group during high pollution, and the disease.

Results of the logistic regression model according to age-wise had shown that in children among 6-7-yearolds there was an association between allergy symptoms such as cough, and significant relation was seen in children aged 13-14 between gender and asthma ( $p=0.003$, $O R=2.58)$.

\section{Discussion}

The prevalence of "ever asthma" among children aged 7-6 years and 14-13 years old has decreased as compared to the previous study in Ahvaz city from $6.8 \%$ to $3.7 \%$ and from $9.8 \%$ to $6.1 \%$, respectively. This level is different in other Iranian cities from $2.1 \%$ to $7.1 \%$ [1215]. This may be due to lack of parental awareness of their child's illness or imprecision of physicians in the diagnosis of asthma in children while this rate in children aged 6-7 has significantly increased from $11.1 \%$ to $24.2 \%$, which can be considered as a warning to health policy. The frequency of severe asthma symptoms such as disrupting breathing and sleep among 7-6-year-olds has declined as compared to the previous study in Ahvaz (from $8 \%$ to $3.6 \%$ and from $10.7 \%$ to $4.2 \%$, respectively), but a slight increase in sleep disorders in individuals aged 13-14 years (from 9.6\% to 9.9\%) and reduction in breathing disorders (from $10.7 \%$ to $9.9 \%$ ) were observed. This can be due to better access to appropriate treatment after diagnosis.

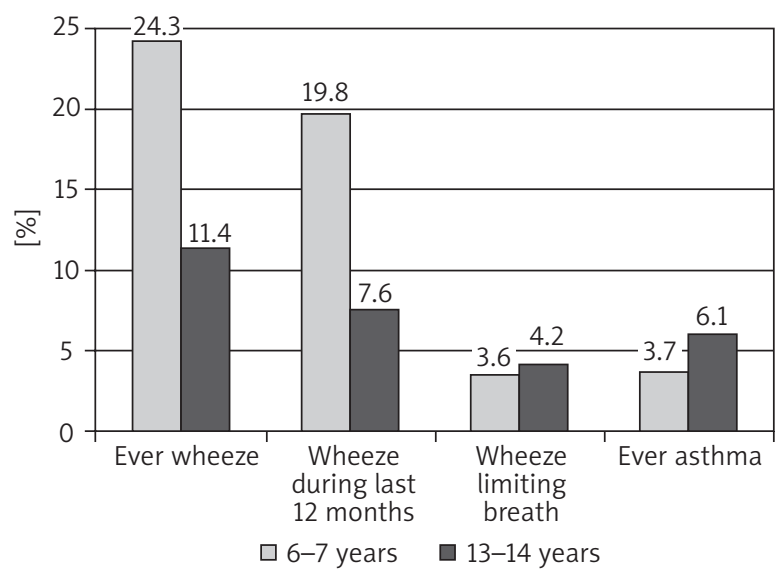

Figure 3. Prevalence of respiratory symptoms in childhood asthma in children aged $6-7$ and $13-14$ years old

In this study there was a significant association between asthma and a history of smoking among other family members for participants aged 13-14. Different studies indicated that passive smokers have more sensitive bronchi, and are vulnerable to asthma and relapse of wheezing in children [16-19]. In our study, no relation between a history of parental smoking in school children aged 6-7 and the disease was found because of a low percentage of mothers who spend many hours at home with their children and smoke.

The finding of this study has shown that prevalence of asthma, ever wheezing, sleep disorders due to asthma, and wheezing after play and exercise is higher in boys than girls. This issue may be due to hormonal changes in women and smaller airways of boys than girls [20].

In the present study, no significant association was observed between consumption of a particular food and asthma, but prevalence of allergic was high in Khuzestan, due to more use of spices. Lack of a significant relation between consumption of a particular food in the ISSAC study and asthma indifferent parts of our country can be due to different dietary habits in various cultures [21].

In our study, $4.8 \%$ of participants answered "yes" to the question "has your child ever had asthma?" while prevalence of asthma according to three questions was $5.4 \%$. It seems that $0.6 \%$ of children's parents were unaware of their child's asthma. This means that they have not taken any medication to treat and prevent asthma attacks.

The limitation of this study was a small sample size. If the sample size is increased, or the study was designed as a cohortor case-control one, non-significant associations between asthma and related risk factors, may be significant. Prevalence of asthma was based on data from the ISAAC questionnaire with focus on symptoms or previous diagnosis of asthma. 
Table 2. Odds ratio of respiratory symptoms in childhood asthma age-wise

\begin{tabular}{|c|c|c|c|c|c|}
\hline Variable & & Age & $\%$ & OR $(95 \% \mathrm{Cl})$ & Value of $p$ \\
\hline \multirow[t]{4}{*}{ Gender } & Male & \multirow{2}{*}{$6-7$} & 48.6 & \multirow[t]{2}{*}{$1.21(0.67-2.18)$} & \multirow[t]{2}{*}{0.55} \\
\hline & Female & & 51.4 & & \\
\hline & Male & \multirow{2}{*}{$13-14$} & 51.1 & \multirow[t]{2}{*}{$2.58(1.37-4.86)$} & $<0.01$ \\
\hline & Female & & 48.9 & & $<0.001$ \\
\hline \multirow[t]{2}{*}{ Ever wheeze } & & $6-7$ & 24.3 & $5.01(2.74-9.17)$ & $<0.001$ \\
\hline & & $13-14$ & 11.4 & $6.27(3.39-11.59)$ & $<0.001$ \\
\hline \multirow{2}{*}{\multicolumn{2}{|c|}{ Wheeze during the last 12 months }} & $6-7$ & 19.8 & $5.08(2.76-9.35)$ & $<0.001$ \\
\hline & & $13-14$ & 7.6 & $6.75(3.44-13.22)$ & 0.061 \\
\hline \multirow[t]{2}{*}{ Wheeze limiting breath } & & $6-7$ & 3.6 & $5.70(2.34-13.95)$ & $<0.001$ \\
\hline & & $13-14$ & 4.2 & $2.06(0.70-6.06)$ & $<0.001$ \\
\hline \multirow[t]{2}{*}{ Ever Asthma } & & $6-7$ & 3.7 & $47.19(21.49-103.63)$ & $<0.001$ \\
\hline & & $13-14$ & 6.1 & $20.02(12.49-32.09)$ & $<0.05$ \\
\hline \multirow[t]{2}{*}{ Wheeze after exercises } & & $6-7$ & 5.3 & $6.73(3.17-14.27)$ & $<0.001$ \\
\hline & & $13-14$ & 12.5 & $2.75(1.41-5.39)$ & 0.13 \\
\hline \multirow[t]{2}{*}{ Dry cough } & & $6-7$ & 16.2 & $2.08(1.53-5.40)$ & 0.84 \\
\hline & & $13-14$ & 19.8 & $1.72(0.90-3.29)$ & $<0.05$ \\
\hline \multirow{2}{*}{\multicolumn{2}{|c|}{ Family history of asthma in the father }} & $6-7$ & 5.5 & $2.37(0.88-6.34)$ & 0.69 \\
\hline & & $13-14$ & 5.5 & $39.3(1.42-8.08)$ & 0.14 \\
\hline \multirow{2}{*}{\multicolumn{2}{|c|}{ Family history of asthma in the mother }} & $6-7$ & 4.6 & $1.17(0.27-5.06)$ & 0.34 \\
\hline & & $13-14$ & 6.9 & $1.98(0.80-4.80)$ & \\
\hline \multirow[t]{2}{*}{ Father's smoking } & & $6-7$ & 18.5 & $0.63(0.26-1.51)$ & 0.50 \\
\hline & & $13-14$ & 27.1 & $1.24(0.66-2.33)$ & 0.60 \\
\hline \multirow[t]{2}{*}{ Mother's smoking } & & $6-7$ & 0.6 & $1.06(1.04-1.07)$ & 0.08 \\
\hline & & $13-14$ & 4.4 & $0.87(0.66-1.15)$ & \\
\hline \multirow{2}{*}{\multicolumn{2}{|c|}{ Other member at home smoking }} & $6-7$ & 4.4 & $0.52(0.07-3.38)$ & 0.52 \\
\hline & & $13-14$ & 5.9 & $3.88(1.69-8.87)$ & 0.001 \\
\hline \multirow{2}{*}{\multicolumn{2}{|c|}{$\begin{array}{l}\text { Sneezing and coughing after rising } \\
\text { air pollution }\end{array}$}} & $6-7$ & 63.13 & & 0.001 \\
\hline & & $13-14$ & 52.42 & & 0.29 \\
\hline \multirow[t]{2}{*}{ Food allergy } & & $6-7$ & 13.45 & & $<0.01$ \\
\hline & & $13-14$ & 39.51 & & 0.08 \\
\hline
\end{tabular}

\section{Conclusions}

Prevalence of asthma in children was higher in males than females and prevalence of allergic symptoms will increase with high air pollution. Family history of asthma was a strong risk factor for childhood asthma.

\section{Acknowledgments}

This study has been financially supported by Ahvaz Jundishapur University of Medical Sciences.

The authors' sincere gratitude is extended to all of the parents and children who participated in the study.

\section{Conflict of interest}

The authors declare no conflict of interest.

\section{References}

1. Azizy F, Janghorbani M, Hatami H. Epidemiology and control of common disease in Iran. Khosravi Publications, Tehran 2011; 342.

2. Masoli M, Fabim D, Holt S, et al. Global Initiative for Asthma (GINA) program: the global burden of asthma: executive summary of the GINA Dissemination Committee report. Allergy 2004; 59: 469-78. 
3. Rutkowski K, Sowa P, Rutkowska-Talipska J, et al. Allergic diseases: the price of civilisational progress. Postep Derm Alergol 2014; 31: 77-83.

4. Shakurnia AH, Assar S, Afra M, Ltifi M. Prevalence of asthma among school children in Ahvaz, Islamic Republic of Iran. EMHJ 2003; 16: 651-6.

5. Leung R, Wong G, Lau J, et al. Prevalence of asthma and allergy in Hong Kong schoolchildren: an ISAAC study. Eur Respir J 1997; 10: 354-60.

6. Bousquet J, Khaltaev N. Global surveillance, prevention and control of chronic respiratory disease a comprehensive approach. WHO, Geneva 2007.

7. Barman SS. The global burden of asthma. Chest 2006; 130 (Suppl.): 4-12.

8. Asher MI, Montefort S, Björkstén B, et al. Worldwide time trends in the prevalence of symptoms of asthma, allergic rhinoconjunctivitis, and eczema in childhood: ISAAC Phases One and Three repeat multicounty cross-sectional surveys. Lancet 2006; 368: 733-43.

9. Kaur B, Anderson HR, Austin J, et al. Prevalence of asthma symptoms, diagnosis, and treatment in 1214 year old children across Great Britain (International Study of Asthma and Allergies in Childhood, ISAAC UK). BMJ 1998; 316: 118-24.

10. Ellwood P, Asher MI, Beasley R, et al. The International Study of Asthma and Allergies in Childhood (ISAAC): phase three rationale and methods. Int J Tuberc Lung Dis 2005; 9: 10-6.

11. Pearce N, Aït-Khaled N, Beasley R, et al. Worldwide trends in the prevalence of asthma symptoms: phase III of the International Study of Asthma and Allergies in Childhood (ISAAC). Thorax 2007; 62: 758-66.

12. Hatami G, Amir Azodi E, Najafi A, et al. Prevalence of asthma and asthma-related symptoms among 13-14 years schoolchildren in Bushehr, ISAAC. Iranian South Med J 2002; 5: 167-75.

13. Reza Masjedi M, Fadaizadeh L, Najafizadeh K, Dokouhaki P. Prevalence and severity of asthma symptoms in children of Tehran: International Study of Asthma and Allergies in Childhood (ISAAC). Iran J Allergy Asthma Immunol 2004; 3: 25-30.

14. Abbasi Ranjbar Z. Prevalence of asthma symptoms in children. J Guilan Univ Med Sci 2006; 56: 1-9.

15. Rahimi Rad MH, Hejazi ME, Behrouzian R. Asthma and other allergic disease in 13-14 year-old school children in Urmia: an ISAAC study. Eastern Mediterr Health J 2007; 13: 1005-16.

16. Forastiere F, Agabiti N, Corbo GM, et al. Passive smoking as a determinant of bronchial responsiveness in children. Am J Respir Crit Care Med 1994; 149: 365-70.

17. Cheraghi M, Salvi S. Environmental tobacco smoke and respiratory health in children. Eur J Pediatr 2009; 168: 897-905.

18. MirSaeid Ghazi B, Sharifi SH, Goodarzipoor K, et al. The prevalence of asthma among the students (7-18 years old) in Tehran during 2002-2003. Iran J Allergy Asthma Immunol 2004; 3: 89-92.

19. Cheraghi M, Dadgarinejad A, Salvi S. A cross-sectional study to find prevalence and risk factors for childhood asthma in Pune City, India. ISRN Public Health 2012; 12: 361456, doi: 10.5402/2012/361456.

20. Mvula M, Larzelere M, Kraus M, et al. Prevalence of asthma and asthma-like symptoms in inner-city schoolchildren. J Asthma 2005; 42: 9-16.

21. Ellwood P, Asher MI, Björksten B, et al. Diet and asthma, allergic rhinoconjunctivitis and atopic eczema symptom prevalence: an ecological analysis of the International Study of Asthma and Allergies in Childhood (ISAAC) data. Eur Respir J 2001; 17: 436-43. 